\title{
Foreign and Russian Experience of Blockchain Digitization by Central Banks, Financial, and Technology Companies
}

\author{
Mokeeva N.N.* Frais V.E. Pankov V.A.
}

\author{
Ural Federal University, Yekaterinburg, Russia \\ *Corresponding author. Email: natmokeeva@yandex.ru
}

\begin{abstract}
One of the main reasons for closer attention to the blockchain technology on the financial market players' part is the expectation that it will eliminate many of the problems and restrictions inherent in the currently used methods of storage, processing, and exchange of financial information. In this vein, central banks of many countries do not stand aside and actively participate in research and development of practical solutions based on blockchain technology in order to expand the payment space, provide the necessary conditions for sustainable growth of the financial sector and increase its level of information security.

With reference to payment services, blockchain technology has a high potential for use in national and international payment systems. Due to the lack of technological restrictions on the instantaneous presentation of information in the nodes registers and the possibility to eliminate financial intermediaries, payments in such systems can be made in a close to real-time mode.

The use of blockchain technology in the payment infrastructure provides a number of advantages, including in terms of increasing the uninterrupted operation and efficiency of payment processes and systems.
\end{abstract}

Keywords: digital technologies, blockchains, payment infrastructure, central banks

\section{INTRODUCTION}

The relevance of research is determined by the rapid development of digital technology against the backdrop of economy globalization. The transition to the digital economy is manifested in business processes digitalization, introduction of digital technologies in the activities of industrial enterprises, organizations, service sector, government authorities, and financial institutions. The digital technologies mastering provides economic entities with undeniable advantages such as improving the efficiency of business processes, improving competitiveness and synergistic effect due to new opportunities for interaction between market participants, expanding prospects for activities based on the use of digital payment systems and digital money. Currently, the most common platforms used for piloting by financial organizations and solution regulators based on blockchain technology are Ethereum, Corda, Ripple, Quorum, Hyperledger Fabric.

The first prototypes and pilot projects were based on relatively "simple" solutions on the Ethereum platform. The results of most of these developments showed a number of advantages of using blockchain technology in the payment infrastructure in terms of improving fault tolerance, restoring systems after failures and data storage reliability. However, such platform features as the consensus mechanism applied, the possibility of unlimited access to payment information give problems in development and implementation of technology for financial and payment systems. Moreover, the further development of these projects and their transfer to new versions of platforms, as well as testing on other platforms, have shown significant progress in regards to ensuring scalability of solutions and information security. Alongside this, the identified problems in piloting solutions allowed us to begin the development of fundamentally new systems.

Currently, digital technologies of exact and multivariate segmentation within the payment infrastructure management are in demand, which is the subject of a research article.

The relevance and discussion of the practical content of the blockchain digital technologies application by financial market participants in Russia and abroad $[21,22]$, determined the goal and objectives, shaped the choice of the research subject. 


\section{ANALYSIS OF THE RECENT ADVANCES AND PUBLICATIONS IN WHICH THIS PROBLEM SOLVING WAS STARTED, THE ALLOCATION OF PREVIOUSLY UNRESOLVED PARTS OF THE GENERAL PROBLEM TO WHICH THIS ARTICLE IS DEVOTED}

The theoretical and methodological background to the research was the provisions of economic and financial science in the classical and modern understanding of the conceptual positions of the financial market theory, scientific publications that reveal the essence and functional patterns of financial instruments, software and methodological developments of market participants.

The methodological apparatus of the research includes methods of systemic, functional, factorial and comparative analysis with the development of analytical models based on the synthesis of modern scientific methods for studying economic and social phenomena. The methodological tools of research are graphical, analytical, statistical and economic-mathematical methods of information processing.

The research information base was made up of federal laws and regulatory acts of the Russian Federation on financial market regulation, analytical materials from research-to-practice conferences, expert information from periodicals, reference materials and electronic sources of information.

The extent of previous research of the chosen topic in various sources can be characterized as limited. Specific research to improve the financial market tools through the use of innovative digital technologies does not fully disclose the use of technological innovations, or do not reflect the entire problems of the chosen topic, are often only sources for review, not considering the various aspects and distinctive features of digitalization as a new financial and economic phenomenon of modern times.

Review of publications by various authors, prepared in terms of empirical and theoretical methods, indicates the ambivalence of approaches to the digital economy formation, and the uncertainty in the financial technologies regulation.

The empirical basis of the research is the works of Russian and foreign scientists and specialists in payment infrastructure, particularly I.A. Tkachenko, A.V. Varnavsky, A.O. Buryakova, Jones, Emily; Zeitz, Alexandra O., Campiglio, Emanuele; Dafermos, Yannis; Monin, Pierre, et al. The information base is quite representative, thus there is a reliable basis for creating a payment infrastructure based on the use of digital technologies.

\section{RESEARCH GOAL DEFINITION AND OBJECTIVES SETTING}

The goal of research is to analyze the effectiveness of existing tools based on blockchain digital technology used in the financial market.

The subject of research is economic relations in the process of using digital technologies, development and application of new tools in the financial market.

\section{PRESENTATION OF THE MAIN RESEARCH MATERIAL WITH FULL SUBSTANTIATION OF THE SCIENTIFIC RESULTS OBTAINED, FORMULATION OF RECOMMENDATIONS}

Among the projects implemented with the support of foreign central banks, the following can be noted. The Jasper project, which main participants were the Bank of Canada, the Payments Canada payment system, the largest Canadian banks, as well as the R3 consortium [1]. The solution on the Ethereum platform was based on a model of transactions in digital depository receipts, which were the underlying asset and formed a balance of claims between the parties for receiving part of their deposits in Canadian dollars placed with the Bank of Canada. Each digital depositary receipt was the basis for receipting the amount constituting the difference between the parties' obligations to each other.

The main objectives of the project were the development of options for the digital assets issuance by the central bank of Canada, as well as an analysis of the possible areas of blockchain technology application. Besides, an analysis of the Ethereum platform capabilities for compliance with the requirements of PFMI (The Principles for financial market infrastructures) was conducted [2].

During the project, a test version of the payment system was launched, the calculations of which were performed using digital assets based on blockchain technology (CADcoin or settlement coin) [3]. To achieve consensus and transaction validation, the PoW (Proof-of-work) mechanism was used. Each bank had the opportunity to transact and fulfill contracts at its own node. Moreover, transaction validation was performed only by a node belonging to R3 [4].

Thus, within the Jasper project, it was possible to ensure the transfer of assets directly between transaction parties without intermediaries using the Corda platform. Within the project, the tasks of delimiting access rights to information in blockchains were solved: information on all transactions was available to validating nodes controlled by the Bank of Canada, while settlement participants had access only to data on transactions in which they acted as a transaction party. The consensus-building mechanism used made it possible to perform settlements according to the DvP and made it possible to perform clearing and posttrading procedures. 
Within the Stella project implemented by the Bank of Japan (BOJ) and the European Central Bank (ECB) based of the Hyperledger Fabric platform, in order to analyze the possibilities of using blockchain technology for payments, settlement processes for deliveries of securities were selected according to the DvP (delivery versus payment) [ $5]$.

Designers have developed 2 types of smart contracts: a simple contract that processes payments without queuing and mutual settling, and a complex contract that uses liquidity-saving mechanisms (LSM). LSM smart contracts had functionality for queuing payments and built-in mutual settlement mechanisms, which were based on the principles existing in BOJ (BOJ-NET) and ECB (TARGET2) payment systems [6].

To test the smart contracts effectiveness, the program code was first run outside the blockchain system, then on one node without implementing the consensus mechanism, and only after that - on the platform using the consensus mechanism. As a result, up to 65 nodes validating information were used.

One of the most important conclusions reached by teams from the Bank of Japan and the European Central Bank is the conclusion about the possibility of blockchain technology to meet the requirements of the payment system, including in terms of performance. The test platform successfully handled the processing of payments in a number of comparable to the number of payments made in the euro zone and Japan. In addition, as part of the testing, it was found that the size of a distributed network has a strong impact on system performance: an increase in the number of nodes leads to a significant increase in the payments processing time.

The second stage of the project involved the system expansion through the use of Corda, Elements, and Hyperledger Fabric platforms. The ability to transact with securities was tested both when finding information about funds and securities in one ledger, and in different ones.

Within the Bank of England project, the main tasks were to determine the possibility of using the Interledger Protocol as a technical solution for making interconnected payments in different currencies in different payment systems, analyzing possible scenarios of information processing, and identifying possible technical problems associated with the payments synchronization [7].

The result of testing was the successful simultaneous processing of cross-border payments in different payment systems.

As part of new SWIFT technologies introduction, in response to the active development and testing of solutions for cross-border transfers based on blockchain technology, SWIFT has taken measures to increase the efficiency of its own financial messaging system.

As a result, SWIFT launched the Global Payment Initiative (GPI), which allows banks to make faster, more transparent and traceable cross-border payments. Currently, more than 160 financial organizations have joined the GPI. It is expected that the final transition to the SWIFT GPI infrastructure will be implemented before the end of 2020 [8].
SWIFT GPI implementation is performed in several stages, each of which is aimed at solving existing problems of correspondent banks in terms of cross-border transfers.

Along with that, SWIFT also began testing the feasibility of using blockchain technology.

New standards were created at the first stage. The SWIFT GPI Tracker technology was launched on May 22, 2017, to increase payment transparency and traceability [9]. Due to the fact that access to the system is through a graphical user interface, it can be integrated into different systems of the bank.

The technology is based on a cloud database, which provides users with the ability to track the payment status from the moment it is initiated until the receipt of funds to the account of the final recipient is confirmed, as well as fees charged at each stage. GPI Tracker is updated both through the financial messaging, and through the use of open interfaces. Each transaction is encoded by the ordering institution by assigning it a unique 36-digit code consisting of numbers and letters of the Latin alphabet.

Information on the payment processing status of each of the organizations is stored in the cloud infrastructure, while data on transactions performed are confidential and protected by special protocols. At the same time, the organizations involved in financial messaging, as well as the transaction parties, can check the payment status and, if it is delayed, understand at what stage it occurred.

Also, within the first stage, a new multilateral Service Level Agreement (SLA) was introduced, to which member banks should comply. The new GPI Observer mechanism will allow users to compare the level of service delivery by specific organizations with SLA standards [10].

In addition, the GPI Directory was created - a list of banks that can send and receive financial messages in the SWIFT GPI, also containing information on the time of accepting payment orders, the currencies with which they work, and whether banks perform an intermediary function within the GPI payments.

The second stage of the SWIFT GPI introduction was implemented in November 2018. Particularly, three technologies were launched:

- $\quad$ Stop and Recall Payment service (gSRP) - the technology allows for instant backout of payments being processed, as well as upon receipt of consent from the end bank, to refund funds that have already received on the destination account [11];

- the gCOV service, which allows for faster receipt of funds to the destination account and the ability to track their status when the sender and payee accounts are not connected to each other;

- advanced payment tracking within the GPI Tracker, even for those transactions which participating banks have not yet transferred to the SWIFT GPI. 
first to tokenize the entire process of bonds issuing and settlement [17]; possibility of applying new technologies, including blockchain technologies, for cross-border payments will be analyzed.

In January 2017, SWIFT announced the launch of testing blockchain technology to verify the real-time reconciliation of Nostro accounts and to increase liquidity. Testing was performed in cooperation with 33 banks within its own sandbox. Preliminary test results were positive, but SWIFT was faced with the fact that blockchain technology should be used universally by all banks making payments through the system, which is difficult to implement in practice. In addition, significant investments will be required to integrate solutions based on blockchain technology into existing systems. At the same time, according to SWIFT, it remains unclear whether the blockchain technology will increase the liquidity of Nostro accounts of financial organizations and reduce their operating costs.

Besides, for a thorough consideration of the relevant ways of using blockchain technology by financial and technology companies in the second half of 2019 on a global scale, it is worth paying attention to the following projects in Europe and the USA:

1. The Deutsche Borse Stock Exchange (Germany) and the Swisscom telecommunications company (Switzerland) successfully conducted pilot transactions for the settlement of tokenized securities through the blockchain platform [12];

2. Microsoft (USA) launched the Azure Blockchain Tokens cloud blockchain platform for issuing corporate Ethereum tokens using ready templates: for example, loyalty programs, letters of credit or tickets [13];

3. Paxos, a US blockchain startup, obtained permission from the US Securities and Exchange Commission to process transactions in the US stock market [14];

4. The German Commerzbank, the Deutsche Bourse exchange and the MEAG fund entered into a securities transaction, the settlement and clearing of which was performed on the "delivery versus payment" on a blockchain platform [15];

5. Wells Fargo Financial Holding (USA) plans to launch the Wells Fargo Digital Cash pilot blockchain service based on the Corda platform for intra-group settlements. [16];

6. One of Spain's largest banks, Santander, issued bonds in the amount of USD 20 million and tokenized quarterly coupons on the Ethereum platform. The Bank was the
7. The German Deutsche Bank has joined the interbank information network based on the Quorum platform. The platform is designed for real-time interbank messaging on crossborder transfers and allows one to speed up the process of making payments that are incorrectly executed or require additional verification for compliance, which may now take several weeks. [18];

8. Mastercard payment system and R3 blockchain consortium announced a strategic partnership, within which a crossborder payment solution based on blockchain technology will be created.

Based on the analysis of pilot projects of regulators, financial market players, technology companies related to the use of blockchain technology for payments, it can be concluded that most of the tests started with platforms that were originally created for private use in mutual settlements using digital tokens (Ethereum, in particular), but in the future, regulators transferred to the study of corporate platforms. This trend is explained by the fact that corporate platforms were initially developed for the specific tasks of financial organizations and taking into account the regulatory requirements of various jurisdictions in the field of payments, requirements to combat laundering of income and financing of terrorism and KYC implementation procedures.

Currently, the main barrier is the cost of developing innovative technologies and finding the right functional niches for their use. This will require the efforts of all participants in the financial market, including from the regulators of different countries. Without necessary legal conditions, protection standards and cybersecurity procedures, as well as supervision and incentive measures, it would be impossible to create such a complex transboundary ecosystem.

\section{FINAL STATEMENT - CONCLUSIONS OF THIS RESEARCH AND PROSPECTS FOR FURTHER DEVELOPMENT OF THIS DIRECTION}

This analysis identified the main areas of activity of Russian companies related to the use of blockchain technology. These are mainly technology companies which core activity is the use of computer technology, software development, and the consulting services provision. However, the Russian market has companies that use tools based on blockchain technology, whose main activity is trade, production of electronic equipment, 
of the platform to develop Ethereum decentralized

telecommunication equipment, biotechnology, and educational activities.

One of the toolkit projects, based on the mechanisms of blockchain technology, was the Bank of Russia project on the cross-border transfers implementation.

In the first half of 2018, the Bank of Russia's Novosibirsk innovative laboratory conducted research on testing the possibility of cross-border settlements using the Ripple platform.

The system technology assumed that the settlement participants had special accounts opened in national payment systems and addresses in the Ripple network.

Reflection of operations in national payment systems could be performed both after each transfer, and at the end of the trading day or at certain intervals.

Based on the research results, it was concluded that the Ripple platform can be considered as the basis for starting work on creating a system of cross-border settlements, provided that the following organizational, legal and technical issues are resolved:

- use for XRP transfers or equivalents of fiat currencies issued by each participant - the national bank;

- determination of a mechanism for reconciling balances between the accounts of Ripple participants and the national payment system;

- use of embedded cryptographic solutions on the Ripple network;

- development of a procedure for determining cross rates for the internal "currency" of Ripple XRP (when deciding to use XRP in interstate settlements);

- maintaining correspondence directories between the addresses of the accounts of Ripple network participants and the accounts of the banks they serve in national payment systems.

In case of using fiat currency equivalents in cross-border transfers, it is necessary to take into account:

- sources of information on proposals for the purchase/sale of currencies, determination of cross-currency exchange rates;

- the impact on organization of market makers;

- $\quad$ source availability and market maker liquidity for each of the currencies used.

The most significant Russian project based on the use of blockchain technology is the Masterchain decentralized network of exchange and storage of information.

The Masterchain platform is a Russian national network based on blockchain technology designed to transfer digital assets and information about them between users. As a basis, the Masterchain platform uses the source code services. At the same time, it was finalized taking into account the requirements of Russian legislation on cryptography, identification of participants, requirements for the implementation of a system to combat laundering of income and financing of terrorism, as well as a safe and efficient scaling process [19].

The stated goals of the projects developed on the Masterchain platform are to optimize economic costs, subject to information security and prevent cyber fraud, as well as reduce the level of paper workflow and create a trusted digital environment for the Russian financial market.

In 2016, the Bank of Russia and the largest Russian financial market participants created the FinTech Association. The founders of the FinTech Association included VTB Bank, Alfa Bank, Qiwi and a number of leading financial and technology companies.

To conduct pilot projects, FinTech Association selected 4 projects that were developed on the Masterchain platform basis:

- decentralized depository system for mortgage accounting;

- "Know Your Customer" project to prevent fraudulent transactions by exchanging information about individuals between participants in the system;

- electronic bank guarantee accounting system;

- launch of digital letters of credit system.

While executing the project of "Decentralized Depository System for Mortgage Accounting", the main goal was to reduce the cost and time of operations for the accounting, storage, and securitization of mortgages. Within the project, depositories form a cloud system for distributed storage of electronic mortgages and accounting for depository accounts activity. The processes between the participants are automated based on the use of smart contracts that comply with the logic of the current Russian legislation. The interaction scheme is presented in Figure 1 .

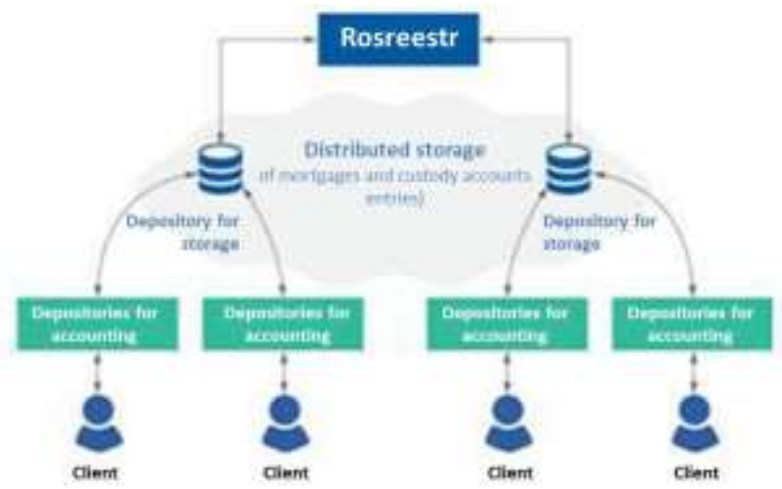

Figure 1 Decentralized Depository System for Mortgage Accounting [20] 
and checking guarantees for all participants in the process: bank, principal, beneficiary. In addition, it aims to increase the security of bank guarantees and reduce the number of fakes on paper, as well as to expand the capabilities of bank guarantees through the use of smart contracts.

The final goal of the project is to create a blockchain of digital bank guarantees issued by banks operating in the Russian Federation and to avoid paper guarantees. It is intended that digital guarantee will be the primary digital document that will be reproduced on paper only if necessary for information purposes. The operation scheme of the digital bank guarantees blockchain is presented in Figure 3 .

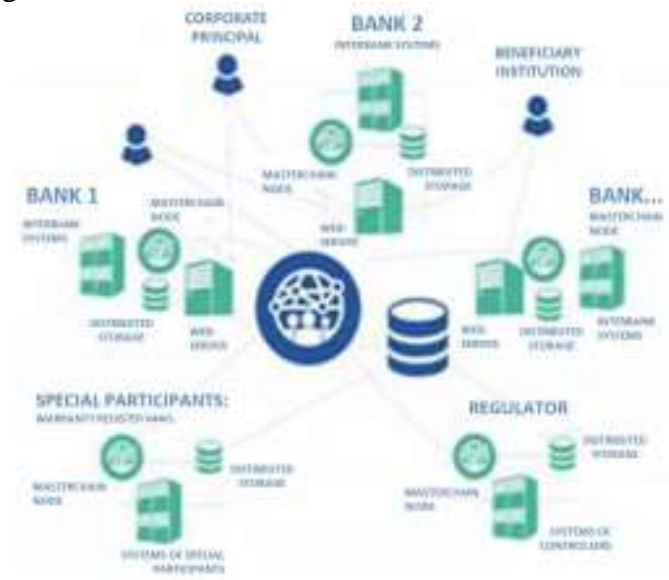

Figure 3 Operation scheme of the digital bank guarantees blockchain [20]

The "Digital Letter of Credit" project is aimed at reducing the terms of execution of transactions on paid letters of credit. The project operation scheme is presented in Figure 4.

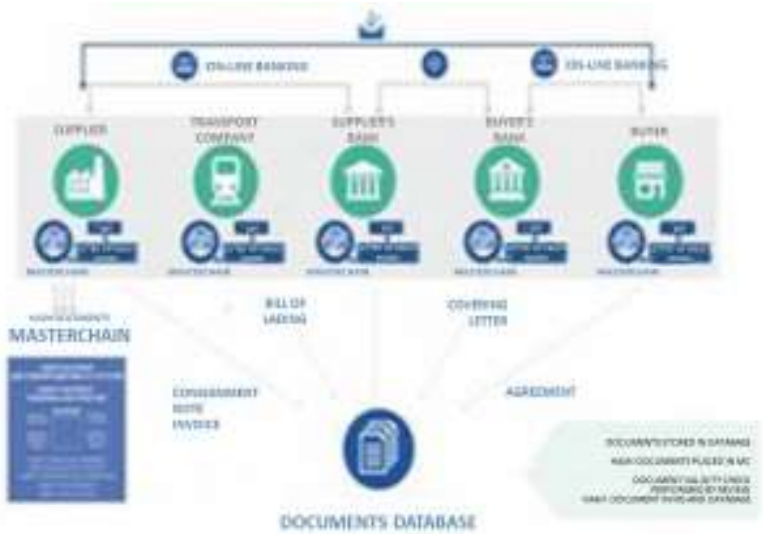

Figure 4 "Digital Letter of Credit" project operation scheme [20]

Its tasks include the exclusion of paper workflow and the associated time delays in transactions, as well as the automation of financial transactions.

In accordance with the current Russian legislation, these projects can be implemented and commissioned after the legitimization of the platform on which they are based.

The project of "Digital Bank Guarantees Blockchain" is designed to reduce labor costs for the process of obtaining 
[7] FinTech Accelerator Proof of Concept. Available at: https://www.bankofengland.co.uk/

[8] SWIFT global payments innovation (gpi). Available at: https://www.rosswift.ru/

[9] SWIFT gpi. Next level cross-border payments. Available at: https://www.coconet.de/

[10] Gpi Observer Analytics. Available at: https://www.swift.com/

[11] Stop and Recall Payment service. Available at: https://www.swift.com/

[12] Deutsche Börse и Swisscom успешно провели транзакции с ценными бумагами через блокчейн. Available at: https://bits.media/

[13] Microsoft To Help Enterprises Mint Their Own Ethereum Tokens. Available at: https://www.forbes.com/

[14] Credit Suisse and SocGen first up for Paxos Settlement Service. Available at: https://www.finextra.com

[15] Deutsche Börse i Commerzbank proveli testovuyu tranzaktsiyu $\mathrm{s}$ ispol'zovaniyem DLT. Available at: https://bits.media/

[16] Wells Fargo vypustit sobstvennuyu kriptovalyutu. Available at: https://www.rbc.ru/

[17] Payment systems: liquidity saving mechanisms in a distributed ledger environment. Available at: https://www.ecb.europa.eu/

[1] Project Jasper. Available at: https://www.payments.ca/

[2] Beyond the doomsday economics of "proof-ofwork" in cryptocurrencies. Available at: https://www.bis.org/

[3] CAD-coin versus Fedcoin Available at: https://www.r3.com/

[4] Proyekt Jasper: vyvody Banka Kanady o pervom proyekte na osnove blokcheyna. Available at: https://bits.media/

[5] Synchronised cross-border payments. Available at: https://www.ecb.europa.eu/

[6] Payment systems: liquidity saving mechanisms in a distributed ledger environment. Available at: https://www.ecb.europa.eu/
[18] Deutsche Bank подключился к блокчейнсети JPMorgan. Available at: http://xn--80aplem.xn-p1ai/

[19] "Mastercheyn" - pervyy yuridicheski chistyy blokcheyn $\mathrm{v}$ Rossii. Available at: http://masterchain.rbc.ru/

[20] Mastercheyn (Masterchain). Rossiyskaya natsional'naya blokcheyn-set'. Available at:http://www.tadviser.ru/

[21] Regulatory Convergence in the Financial Periphery: How Interdependence Shapes Regulators' Decisions/Jones, Emily; Zeitz, Alexandra O. INTERNATIONAL STUDIES QUARTERLY Volume: 63 Issue: 4 Pages: 908-922 Published: DEC 2019

[22] Climate change challenge for central banks and financial regulators/Campiglio, Emanuele; Dafermos, Yannis; Monin, Pierre; with co-authors. NATURE CLIMATE CHANGE Volume: 8 Issue: 6 Pages: 462-468 Published: JUN 2018. 